\title{
Management of trichiasis with lid margin split and cryotherapy
}

This article was published in the following Dove Press journal:

Clinical Ophthalmology

8 November 2012

Number of times this article has been viewed

\author{
Amr Khafagy' \\ Mostafa Mahmoud Mostafa ${ }^{2}$ \\ Fathi Fooshan ${ }^{3}$ \\ 'Department of Ophthalmology, Cairo \\ University, Cairo, Egypt; ${ }^{2}$ Department \\ of Ophthalmology, Al-Azhar University, \\ Cairo, Egypt; ${ }^{3}$ Department of \\ Ophthalmology, Misr University for \\ Science and Technology, Cairo, Egypt
}

Purpose: To evaluate outcomes of lid margin split with cryotherapy to the anterior lid lamella for treating trichiasis.

Methods: This prospective study included 20 eyelids of ten patients with trichiasis who were treated with lid margin split and cryotherapy. All patients were followed up for 6 months.

Results: Eighteen eyelids (90\%) were successfully treated, and two eyelids (10\%) developed recurrence within the follow-up period.

Conclusion: Lid margin split with cryotherapy is an effective and safe method for treating trichiasis.

Keywords: trichiasis, lid margin split, cryotherapy

\section{Introduction}

Trichiasis is an acquired condition in which the lashes are maldirected posteriorly toward the surface of the eye. It can present with only a few eyelashes in a segmental or diffuse pattern. ${ }^{1}$ Trichiasis is commonly seen in trachoma, chronic blepharitis, cicatricial eye inflammation, and alkali burn. ${ }^{2}$

Many modalities of therapy have been used to treat trichiasis. These include mechanical epilation, electrolysis, argon and diode laser therapy, radio frequency, cryotherapy, and lid surgery. ${ }^{3}$ Cryotherapy is an effective method for treating large, confluent areas of trichiasis; however, it is associated with significant risk of complications, including lid depigmentation, lid notching, and xerosis. ${ }^{4}$ The technique of eyelid splitting at the gray line with selective cryotherapy to the anterior lid lamella may avoid eyelid pigmentary changes and also damage to adjacent structures. ${ }^{5}$

The aim of this study was to evaluate the outcome of combined eyelid splitting with selective cryotherapy to the anterior lid lamella for treating a trichiasis-involved large segment of the lid margin.

\section{Patients and methods}

This prospective study included 20 eyelids of ten patients with trichiasis, who were treated with combined eyelid splitting and selective cryotherapy to the anterior lid lamella. The study was conducted at Noor Alhaya Eye Hospital from April 2011 till December 2011.

Correspondence: Mostafa Mahmoud Mostafa

93 Elmarghany St. 4th floor,

Noor Alhaya Eye Hospital,

Misr Algadeda, Cairo, Egypt

Tel +20 II 4 II 88007

Email mostafamahmoudd@gmail.com

\section{Inclusion criteria}

- Trichiasis of upper eyelid

- Trichiasis involving one-third to half the length of the lid margin

- Number of trichiatic lashes $>10$ (Figure 1). 


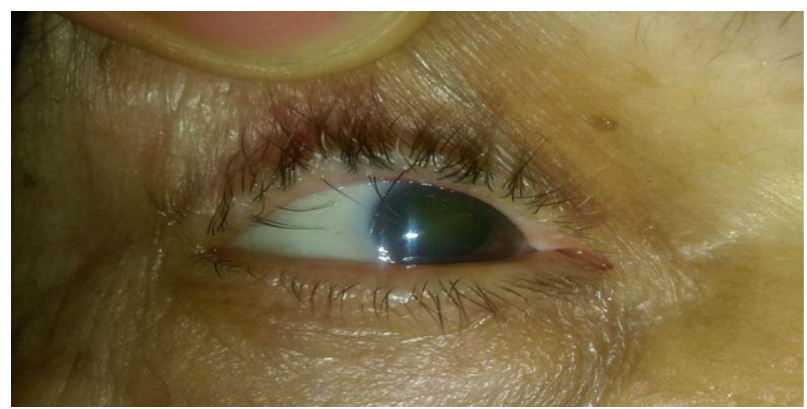

Figure I Preoperative case.

\section{Exclusion criteria}

- Patients who had trichiasis that involved the whole length of the eyelid margin

- Patients who had associated entropion or lid scarring.

Before treatment, a detailed history was taken from all patients, including duration of symptoms related to trichiasis (foreign-body sensation, lacrimation) and history of previous treatment for trichiasis. Then, a complete ophthalmic examination was performed on all patients, including a detailed examination of the eyelid to determine the exact site and number of trichiatic lashes and to detect any associated entropion or lid scarring, and also to search for the possible underlying etiology of trichiasis. Informed consent was obtained after explaining the modality of treatment to all patients who agreed to be included in this study.

\section{Technique of lid margin split with cryotherapy to the anterior lid lamella}

In the operating theater under topical and local infiltration anesthesia with complete aseptic condition, the lid margin was split at the gray line along the affected segment of eyelid margin to expose trichiatic lash follicles in the anterior lamella to treat with cataract cryoprobe using a doublefreeze-thaw technique.

During the freezing phase, the cataract cryoprobe was placed until an ice ball formed $\left(-60^{\circ} \mathrm{C}\right)$ and maintained for 8 seconds. The freezing phase was followed by thawing to room temperature by irrigation with physiological saline. A refreeze was done and maintained for 8 seconds, followed by rapid thawing to room temperature by irrigation with physiological saline to ensure complete destruction of trichiatic lash follicles. Then, the anterior and posterior lamellae were repositioned with each other without suturing.

Postoperatively, we prescribed antibiotic eye ointment and lubricant for 1 week to all patients (Figure 2). All patients were followed every week for 1 month, then monthly

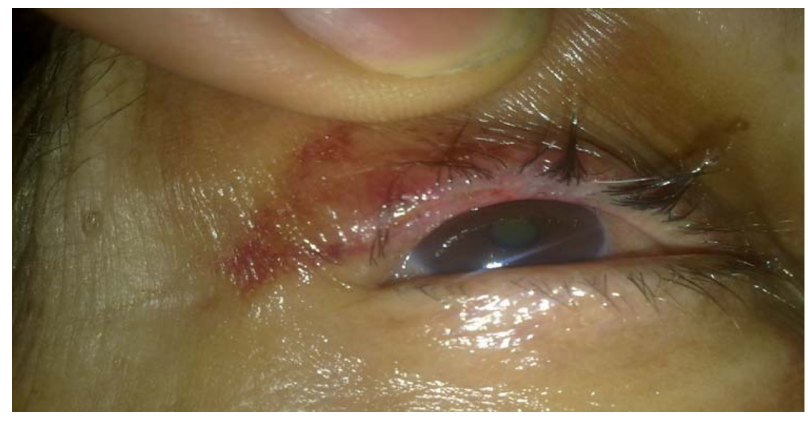

Figure 2 Postoperative photography of the case in Figure I.

for 6 months. During each visit, a complete ophthalmic examination was done, including detailed examination of the eyelid to detect any recurrence. Any complication was recorded.

\section{Results}

A total of 20 eyelids of ten patients were treated. The mean age of the patients was $45 \pm 3.8$ years, and the ratio of males to females was 2:3. The upper eyelid was involved in all eyes. Eight patients (16 lids) (80\%) were treated previously with repeated epilation, and two patients (four lids) (20\%) with electrolysis.

Eighteen lids of 18 patients (90\%) were successfully treated with eyelid splitting and cryotherapy for trichiasis. Two lids of two patients (10\%) developed recurrent trichiasis in the previous treated area within the follow-up period. No significant complications were noticed, although mild lid edema occurred in all patients postoperatively, which resolved within 1 week.

\section{Discussion}

Trichiasis is a very common problem encountered in clinical practice in the Middle East, especially that related to trachoma. ${ }^{6}$ If left untreated, it can lead to corneal ulceration and scarring and eventually result in impairment of vision. ${ }^{7}$ Interestingly, we found that trachoma was the only underlying cause of trichiasis in all patients in this study.

To the best of our knowledge, there are no other studies in the literature discussing the use of eyelid splitting combined with cryotherapy to the anterior lid lamella for treatment of trichiasis. However, there are several studies reporting the use of eyelid splitting with cryotherapy to posterior lid lamella for treatment of distachiasis. ${ }^{8,9}$

In the present study, we demonstrated a success rate of $90 \%$ for treating patients with trichiasis involving a large segment of the lid margin with lid margin split combined 
with selective cryotherapy to the anterior lid lamella using a double-freeze-thaw technique. This was consistent with previous studies, which have shown success rates of $90 \%$ with cryotherapy using the double-freeze-thaw technique. ${ }^{10,11}$ Also in this study, no significant complications, such as lid depigmentation and lid notching, were noted compared to previous studies that used cryotherapy alone for treating their patients with trichiasis. ${ }^{12,13}$

\section{Conclusion}

The technique of lid margin split with selective cryotherapy to the anterior lid lamella is effective and safe for treating patients with a large number of trichiatic lashes distributed over a large segment of the lid margin.

\section{Disclosure}

The authors report no conflicts of interest in this work.

\section{References}

1. Choo P. Distichiasis, trichiasis, and entropion: advances in management. Int Ophthalmol Clin. 2002;42:75-87.
2. Kaltreider SA. Trichiasis. In: Roy FH, Tindall R, editors. Master Techniques in Ophthalmic Surgery. Baltimore: Williams and Wilkins; 1995:509-519.

3. American Academy of Ophthalmology. Basic and Clinical Science Course Section 7: Orbit, Eyelids, and Lacrimal System. San Francisco: American Academy of Ophthalmology; 2007.

4. Johnson RLC, Collin JRO. Treatment of trichiasis with a lid cryoprobe. Br J Ophthalmol. 1985;69:267-270.

5. Ferreira IS, Bernardes TF, Bonfioli AA. Trichiasis. Semin Ophthalmol. 2010;25:66-71.

6. Resnikoff S, Pascolini D, Etya'ale D, et al. Global data on visual impairment in the year 2002. Bull World Health Organ. 2004;82:844-851.

7. Kormann RB, Moreira H. Treatment of trichiasis with high-frequency radio wave electrosurgery. Arg Bras Oftalmol. 2007;70:276-280. Portuguese.

8. O'Donnel BA, Collin JR. Distichiasis: management with cryotherapy to the posterior lamaella. Br J Ophthalmol. 1993;77:289-292.

9. Anderson RL, Harvey JT. Lid splitting and posterior lamella cryosurgery for congenital and acquired distichiasis. Arch Ophthalmol. 1981;99:631-634.

10. Collin J, Coster D, Sullivan J. Treatment of trichiasis with a lid cryoprobe. Br J Ophthalmol. 1985;69:267-270.

11. Delaney MR, Rogers PA. A simplified cryotherapy technique for trichiasis and distichiasis. Aust J Ophthalmol. 1984;12:163-166.

12. Rice C, Kersten R, Al-Hazzaa S. Cryotherapy for trichiasis in trachoma. Arch Ophthalmol. 1989;107:1180-1182.

13. Elder MJ, Bernauer W. Cryotherapy for trichiasis in ocular cicatricial pemphigoid. Br J Ophthalmol. 1994;78:769-771.
Clinical Ophthalmology

\section{Publish your work in this journal}

Clinical Ophthalmology is an international, peer-reviewed journal covering all subspecialties within ophthalmology. Key topics include: Optometry; Visual science; Pharmacology and drug therapy in eye diseases; Basic Sciences; Primary and Secondary eye care; Patien Safety and Quality of Care Improvements. This journal is indexed on

Submit your manuscript here: http://www.dovepress.com/clinical-ophthalmology-journal

\section{Dovepress}

PubMed Central and CAS, and is the official journal of The Society of Clinical Ophthalmology (SCO). The manuscript management system is completely online and includes a very quick and fair peer-review system, which is all easy to use. Visit http://www.dovepress.com/ testimonials.php to read real quotes from published authors. 